\title{
Mathematical Formalization OF THEORIES OF motivation proposed by MASLOW and Herzberg
}

Ivan Kotliarov ${ }^{\star}$

\begin{abstract}
s
Maslow's theory is by far the most known theory of motivation, and the most common in the business and management practice. Herzberg's theory fits the observations and explains some aspects of human motivation left unexplained by Maslow. However, these theories have never been formalized on a strictly mathematical basis. The present article gives an outline of a mathematical model of theories of motivation proposed by Abraham Maslow and Frederick Herzberg. This model is built on a basis of special non-continuous functions. This description may be a good basis for HR software and may be useful for business and management.
\end{abstract}

Keywords: motivation; theories of motivation; mathematical modeling; stimuli.

\section{INTRODUCTION}

The theory of Abraham Maslow - his famous hierarchy of needs - is by far the most known theory of motivation, and the most common in the business and management practice. It also provides a reasonably good fit with the experimental data. Frederick Herzberg's theory, while being less popular, also fits the observations and explains some aspects of human motivation left unexplained by Maslow. However, despite their popularity, these theories, to the best of my knowledge, have never been formalized on a strictly mathematical basis. Indeed, there were some attempts to formalize the Maslow's model, but the authors of these attempts oversimplified this model so that it lost its specific features.

In the present article I will try to describe these two theories from the mathematical point of view.

\section{Maslow's Theory}

Maslow's theory of motivation is based on the following axioms (MASLOW, 1999):

1. Human motivation is determined by human needs;

2. Human needs can be rated depending on their priority, thus forming an hierarchy. This hierarchy can be graphically represented as a pyramid;

\footnotetext{
^ Assistant professor in Saint-Petersburg State University (Russia). 7-9, Universitetskaya nab., St. Petersburg, 199034, Rússia.

E-mail:1rpg@mail.ru
} 
3. This hierarchy is the same for all people;

4. People start satisfying their needs from the lowest level;

5. Human motivation is determined by the lowest unsatisfied need;

6. At any given moment the human motivation is determined by needs from one level. It means that needs from higher levels start influencing the human behavior only after the lower needs have been completely satisfied and that the satisfied needs (from lower levels) do not have any influence on the human behavior.

The axiom 5, while used in the original Maslow's model, had been rejected by his followers, so now it is believed that the human behavior can be determined by needs from several levels. All other axioms remain unchanged.

In order to simplify the model let us suppose that the employee can satisfy his/her needs from his/her income only. This approach may seem to be oversimplistic, but is stays on a solid logical basis. Let us study this situation in detail.

Indeed, the salary is not the only mean of remuneration: the employer usually uses other forms of benefits like different honors, promotion, all types of special prizes etc. But it is obvious that all these benefits have a financial equivalent. So the employer have a choice: either he can include the cash equivalent of these benefits into his employee's salary or he can give the employee these benefits. In the latter case the price of these benefits is withdrawn from the potential total income of the employee (the amount he/she would have received in the former case). So the employee virtually paid for satisfaction of his/her needs by these benefits as their price was deduced from his/her potential total income, which, therefore, can be considered as the only mean of satisfaction of human needs.

Let us introduce the following symbols:

$M$ - human motivation;

$D$ - total potential income;

$A_{i}$ - threshold of satisfaction of the needs of the $i$-th level. This value characterizes the total potential income: if $D>A_{i}$ then the needs from the $(i+1)$-th level start influencing the human behavior. At the same time the needs of the уровня $i$-th level continue determining the human motivation;

$B_{i}-$ threshold of saturation of the needs of the $i$-th level. This value is equal to the total potential income that ensures the complete satisfaction of the needs of the $i$-th level so that they stop participating in this employee's motivation;

$M_{i}$ - contribution of the needs of the $i$-th level to the total motivation. It shows how the total human motivation $M$ depends on the degree of satisfaction of the needs of the $i$-th level. We will use the term "partial motivation" as a synonym.

It is logical to suppose that the contribution $M_{i}$ of the needs of the $i$-th level to the total motivation is maximal when the employee starts satisfying these needs 
(when $D$ is equal to or slightly above $A_{i-1}$ ). Later, as the income is grows and provides the possibility to purchase additional goods to satisfy these needs, the marginal utility of each unit of these goods decreases, and so does the contribution $M_{i}$.

Taking into account all these facts and hypotheses we may represent $M_{i}$ by an exponential function of $D, A_{i}$ and $B_{i}$ :

$$
M_{i}=C_{i} e^{-\frac{D-A_{i-1}}{B_{i}-D}}
$$

$C_{i}$ - a constant for the $i$-th level of needs.

It is important to remember that the formula (1) is just a hypothesis. It should be checked experimentally. It may well be, for example, that $C$ is a function, not a constant.

One can easily see that the formula (1) has no sense when $D<A_{i-1}$ and $D>B_{i}$. Therefore it should be modified so that:

1. It had sense at any $D$;

2. It take into account the discrete character of the Maslow's model - spontaneous participation of needs of higher level when a certain value of $D$ is reached.

In my opinion this task can be performed thanks to the modified Heavyside function $\operatorname{Heav}(x)$ :

$$
\operatorname{Heav}(x)= \begin{cases}0, & x \leq 0 \\ 1, & x>0\end{cases}
$$

So the formula (1) will look as follows:

$$
M_{i}=C_{i} e^{-\frac{D-A_{i-1}}{B_{i}-D}} \operatorname{Heav}\left(D-A_{i-1}\right) \operatorname{Heav}\left(B_{i}-D\right)
$$

Maslow's theory says nothing about the concrete form of correlation between the total and the partial motivation. For simplicity sake we may suppose that this correlation is additive, therefore:

$$
M=\sum_{i=1}^{5} M_{i}
$$

or, according to the formula (3),

$$
M=\sum_{i=1}^{5} C_{i} e^{-\frac{D-A_{i-1}}{B_{i}-D}} \operatorname{Heav}\left(D-A_{i-1}\right) \operatorname{Heav}\left(B_{i}-D\right) .
$$


The formula (5), in my opinion, adequately represents the Maslow's theory and corresponds to the axioms 1-5 listed above. This mathematical description can be developed further if we find (theoretically or experimentally) the precise correlation between $M_{i}$ and $D, A_{i}$ and $B_{i}$.

The formulae of the form (5) can be used to mathematically represent most content theories of motivation. As the main difference between these theories is the number of groups of needs taken into account, then the formula (5) can be written down as:

$$
M=\sum_{i=1}^{n} \mathrm{f}_{i}\left(D, A_{i-1}, B_{i}\right) \operatorname{Heav}\left(D-A_{i-1}\right) \operatorname{Heav}\left(B_{i}-D\right),
$$

Where:

$n$ - number of groups of needs;

$\mathrm{f}_{i}$ - functions describing the contribution of the $i$-th group needs to the total motivation. The precise from of these functions should be established experimentally.

It is also important to remember that there are other mathematical models of human motivation - for example, a vector model developed by the author of the present article (KOTLIAROV, 2008) which includes the Maslow's model as a special case. However, the formula (5) is the best representation of the Maslow's theory from the qualitative point of view as it takes into account one of the most important features of this theory - its discrete character.

\section{HERZBERG'S THEORY}

According to Frederick Herzberg, there are two types of factors of influence of the job ans the job atmosphere on the psychological condition of the employee (MESCON; ALBERT; KHEDOURI, 1992):

1. Hygiene factors (describe the job environment - administration policy, technical conditions etc) - if their level is too low, than the employee feels dissatisfaction. If the hygiene factors reach a certain level (and exceed it) then this dissatisfaction disappears, but no satisfaction appears instead. Increase of hygiene factors cannot motivate the employee;

2. Motivations (are linked to the character of the job - promotion, approval etc) - if their level is too low, it will not lead to dissatisfaction. However, if the motivations reach a certain level, then the employee feels satisfaction and is motivated to work better. In order to avoid confusion I will use the term stimuli instead of motivations.

It is logical to suppose (however, it is not stated explicitly in the original Herzberg's model) that every employer has a basic level of motivation non equal to zero. It can be explained by the fact that the employees need a job - the job may not be interesting, promising, clean etc, but it still provides them with salary. 
Therefore, each employee is interested in having a job and has a basic motivation to work well enough in order not to loose this job. As far as I know, this important statement was not used before within the Herzberg's model. As we will see below, this statement substantially simplifies the formalization of this theory.

Obviously every employee has his/her own level of basic motivation $M_{b}$.

The overall motivation of the employee will be determined by the impact of the hygiene factors and stimuli on his/her basic level of motivation.

Let us use the following symbols:

$S_{i}$ - level of the stimuli of the $i$-th group;

$S L_{i}$ - saturation level of the stimuli of the $i$-th group (if the actual value of the stimuli of this group exceeds the saturation level then the motivation of the employee will grow);

$n$ - number of groups of stimuli;

$H_{j}$ - level of the hygiene factors of the $j$-th group;

$H L_{j}$ - saturation level of the hygiene factors of the $j$-th group (if the actual value of the hygiene factors of this group is below this saturation level then the motivation of the employee will decrease);

$m$ - number of groups of hygiene factors.

One can easily see that the total motivation of the employee can be calculated on a basis of the following formula:

$$
M=M_{b}+\sum_{i=1}^{n} \mathrm{~F}_{i}\left(S_{i}-S L_{i}\right) \operatorname{Heav}\left(S_{i}-S L_{i}\right)-\sum_{j=1}^{m} \mathrm{~K}_{j}\left(H L_{j}-H_{j}\right) \operatorname{Heav}\left(H L_{j}-H_{j}\right),
$$

Where the functions $\mathrm{F}_{i}\left(S_{i}-S L_{i}\right)$ and $\mathrm{K}_{i}\left(H L_{j}-H_{j}\right)$ describe the influence of the hygiene factors and stimuli (or, better, of their deflection from the saturation level) on the total motivation. The precise form of these functions is unknown, but one can cautiously suppose that they follow one of the psychophysical laws. If we adopt the Weber-Fechner law (JAVORSKIJ; DETLAF, 1979), then the formula (7) will have the following form:

$$
M=M_{b}+\sum_{i=1}^{n} Z_{i} \lg \frac{S_{i}}{S L_{i}} \operatorname{Heav}\left(S_{i}-S L_{i}\right)-\sum_{j=1}^{m} Y_{j} \lg \frac{H L_{j}}{H_{j}} \operatorname{Heav}\left(H L_{j}-H_{j}\right) .
$$

The formula (9) is an adequate mathematical formalization of the Herzberg's theory of motivation. Of course, the Weber-Fechner law can be replaced by the Steven's law, in this case the formula (7) can be easily modified. 


\section{Conclusion}

The proposed mathematical descriptions of the qualitative models of Maslow and Herzberg are the first ever attempts of formalization of these theories. This description may be a good basis for HR software and therefore may be useful for business and management.

Further research in this field should, in my opinion, be directed towards the precise form of the functions $\mathrm{F}_{i}\left(S_{i}-S L_{i}\right)$ and $\mathrm{K}_{j}\left(H L_{j}-H_{j}\right)$. The precise form of the formula (1) is also yet to be found.

Of course, it is necessary to develop special procedures for definition of the parameters $A_{i}$ and $B_{i}$ for the Maslow's model and $M_{b}, S L_{i}$ and $H L_{j}$ for the Herzberg's models. Without these procedures the proposed models would be useless for practical tasks.

\section{REFERENCES}

JAVORSKIJ, B. M.; DETLAF, A. A. Spravochnik po fizike dlja inzhenerov $i$ studentov vuzov. Moscow: Nauka, 1979.

KOTLIAROV, I. Labour motivation: an axiomatic vector model. Anales de psicología, Murcia, v. 24, n. 1, p. 58-63, jun. 2008. Universidad de Murcia. Available online at http://www.um.es/analesps/v24/v24_1/08-24_1.pdf.

MASLOW, A. G. Motivacija i lichnost'. St. Petersburg: Evrazija, 1999. Translated from English.

MESCON, M.; ALBERT, M.; KHEDOURI, M. Osnovy menedzhmenta. Mpscow: Delo, 1992. Translated from English.

Recebido em: julho de 2008

Aceito em: novembro de 2008 